\title{
The Relationship between Hospital Employee Overall Readiness and Turnover Intentions
}

\author{
Dr. David Augustine Bull, DBA, Ph.D., MBA., M.Sc. B.Sc. CALM. \\ Adjunct Faculty, Colorado Christian University
}

\begin{abstract}
The relationship between employee readiness and turnover intentions was investigated among $(\mathrm{N}=48)$ supervisors and $(\mathrm{N}=192)$ subordinates, men and women between the ages 18 to 65 , randomly selected from four randomly selected hospitals within the southern region of the United States. Instrumentation for the study included the Blanchard, Hersey and Hambleton (1977) Readiness Scale, the Jackofsky and Slocum's (1987) Turnover Intent Scale, and Demographic questionnaire. Statistical analysis using SPSS 24 software included Pearson correlation, Paired $t-$ test, Independent $t$ - test, and Descriptive statistics. Results of the paired t-test failed to show any significant differences between Staff Rated Total Readiness (SRTR) and Supervisor Rated Total Readiness (SRTR). However, an independent sample $t$ - test revealed a statistically significant difference between the mean scores in Total Readiness (TR) for clinical and nonclinical staff. A Pearson correlation matrix for Staff Rated Job Readiness (SRJR), Staff Rated Psychological Readiness (SRPR), and Staff Rated Total readiness (SRTR); and Supervisor Rated Staff Job Readiness (SSRJR), Supervisor Rated Psychological Readiness (SSRPR), and Supervisor Rated Total Readiness (SSRTR), and Turnover Intentions (TI) revealed sufficient evidence of a significant positive correlation between Staff Self-Rated Job Readiness (SRJR) and Staff Self-Rated Psychological Readiness (SRPR) ( $r=.837, p=.000$; Supervisor Rated Staff Job Readiness (SRSJR) and Supervisor Rated Psychological Readiness (SRPR) $r=.843, p=.000$; Staff SelfRated Job Readiness (SRJR) and Supervisor Rated Staff Psychological Readiness (SRPR) $r=.832, p=.000$. In terms of turnover intent, there was significant negative correlation between Job Readiness, Psychological Readiness, Total Readiness and Turnover Intent [TI - SRJR $(r=-.143, p=.026), \mathrm{TI}-\mathrm{SRPR}(r=-.133, p=.040), \mathrm{TI}-\mathrm{SSRJR}(r=-$ $.140, p=.030), \mathrm{TI}-\operatorname{SSRPR}(r=-.137, p=.034)]$ among employees.
\end{abstract}

Keywords: Turnover Intentions, Leadership Style, Psychological Readiness, Employee Readiness



Dr. David Bull is an
adjunct faculty of
Healthcare
Administration and
Business at Colorado
Christian University.
His primary areas of
teaching are
Healthcare
Administration and
Management,
Healthcare Law,
Policies and

Regulations, Healthcare Delivery Systems, and Statistics in Healthcare. Dr. Bull hold a DBA in Business Administration from Columbia Southern University, a Ph.D. in Human Services specializing in Healthcare Administration from Capella University, an MBA in Healthcare Management from Columbia Southern University, and an MS degree in Agronomy from Zhejiang University in China.

Dr. Bull joined Colorado Christian University, College of Adult and Graduate Studies in 2013. He is a subject matter expert in most of the healthcare courses and has worked with many universities both at home and abroad on matters regarding healthcare curriculum. He works with Walden University as contributing faculty and as a member of the doctoral dissertation committee. He is the lead faculty for healthcare administration at the American Intercontinental University - Houston Campus. His experience also extends to the clinical field where he has worked with many hospitals as a behavioral health counselor for many years. Dr. Bull is a member of the American Public Health Association, American College of Healthcare Executives, American Management Association, National Society of Leadership and Success, and National Association of Long-Term Care Administrator Boards. He is a pastor at Assembly for Christ International Ministries, a church where he frequently delivers sermons and teachings to his congregation. He also presents teachings on social media including Facebook and Youtube.

He can be contacted in the following ways:

Email: davidbull62@gmail.com;

Tel: 8325744396

LinkedIn: https://www.linkedin.com/in/dr-davidbull-22453795/ 


\section{INTRODUCTION}

Hospital administrators have been very concerned with the rate of turnover among their employees and have been seeking ways to mitigate this menace (Rosenbaum, 2018). Many experts have recommended the increased involvement of leadership, especially in the area of resource availability and modification of leadership styles in order to encourage employees. One of the most effective leadership styles in this discourse is the use of the Situational Leadership Model (SLM) (Hersey et al., 2013). Researchers have conducted many studies using the SLM as conceptual framework. Some of these studies are linked with turnover intent and thoughts of quitting (For example, Bull, 2018). Bull supported the recommendations of Hersey et al (2013) urging healthcare managers to apply their leadership styles based on situations as presented and the willingness of the employee to complete a given task. Many managers have ignored employee willingness, paying attention to the ability of the employee as a paramount factor in production. Managers have associated turnover and turnover intent with the lack of benefits, low salaries, ineffective leadership styles, and so on, hardly considering the readiness of the employee. While turnover intent has been investigated for these same reasons and more, hardly has the readiness of the follower been considered as a factor in turnover studies, especially in hospitals within the Southern region of the United States.

In this study, the research examined the relationship between employee overall readiness and their turnover intentions within the hospital setting. The researcher used the SLM as conceptual framework. The basis of the premise of the SLM is that, effective leaders match their leadership style to the readiness level of the follower/employee. Please note that the term readiness in this context also means willingness, maturity, or developmental level of the employee or follower to complete a given task. Employee readiness comprises of Readiness level of the employee to complete a given task/Job - Job Readiness, and mental or Psychological Readiness of the employee to complete the same task. The Job Readiness and Psychological Readiness form the Total Readiness level of the employee to complete a given task. The researcher prefers to use readiness for consistency purposes. The readiness of the follower is the situational variable in the SLM. The hypothesis here is, if all other things remain constant, a willing or ready employee would hardly place emphasis on churning or turnover or quitting their job. Although leadership style plays an important role here, this investigation did not emphasize leadership style. The emphasis is placed on the follower's intention to stay on the job or quit the job based on their total readiness level for the job.

The researcher would like to note that the role demographic characteristics such as age, gender, ethnicity, experience, and educational level in relation to employee's Total Readiness, or intention to quit, or stay on a job, were not considered in this study. Even though there may be documented evidence of the influence of these variables of the readiness of an employee, the specific influence of each of these variables were not considered. The researcher intends to examine these demographic factors in an upcoming article, especially the case of generational disparity in employee readiness in relation to staying or quitting a job.

\section{Research Questions}

The following research questions guided the study:

Research Question 1: What is the relationship between staff member perceived self-rated and supervisor perceived rated job, psychological, and total readiness? Hypothesis 1

H1a: There is statistical significance between staff member perceived self-rated and supervisor perceived rated job, psychological, and total readiness?

H1o: There is no statistical significance between staff member perceived self-rated and supervisor perceived rated job, psychological, and total readiness?

Research Question 2: What is the relationship between employee readiness and turnover intentions (TI).

Hypothesis 2

$\mathrm{H} 2 \mathrm{a}$ : Employee readiness is significantly positively corrected with TI

$\mathrm{H} 2 \mathrm{o}$ : Employee readiness is significantly negatively corrected with TI

Research Question 3: Are there differences between clinical and non-clinical employees in relation to their perceived total readiness?

Hypothesis 3

H3a: There is statistical significance between clinical and non-clinical employees in relation to their perceived total readiness.

H3o: There is no statistical significance between clinical and non-clinical employees in relation to their perceived total readiness.

Research Question 4: Are there differences in mean scores between staff member self-rated and supervisor rated job, psychological, and total readiness?

Hypothesis 4

$\mathrm{H} 4 \mathrm{a}$ : There is statistical significance in mean scores between staff member self-rated and supervisor rated job, psychological, and total readiness.

H4o: There is no statistical significance in mean scores between staff member self-rated and supervisor rated job, psychological, and total readiness.

The premise of the study is, if managers effectively match their leadership styles with the appropriate readiness levels of their followers, then absenteeism, tardiness, and turnover will be greatly reduced. In this study, leadership style was not assessed, neither was the influence of demographic characteristics in relation to employee readiness. However, employee readiness and turnover 
intentions were examined. If employees show readiness to complete a given task, then readiness as a whole (Total Readiness), will be negatively correlated with turnover intentions (TI). This hypothesis was tested in this study.

\section{CONCEPTUAL FRAMEWORK AND LITERATURE REVIEW}

\section{A. Conceptual Framework}

The researcher deployed the SLM as the conceptual framework for this investigation. The SLM posits that leaders must lead their followers based on the situation (i.e., the Readiness, Willingness, Maturity, Developmental level) of the follower. The model further suggested that effective leaders are in fact, those who vary their leadership styles along the performance matrix (Hersey et al, 2013). The SLM reveals four leadership dimensions namely telling (S1), selling (S2), participating (S3), and delegating (S4) leadership dimensions in relation to their corresponding Employee Readiness - R1 (Unable or insecure or Unwilling), R2 (Unable but confident or willing), R3 (Able but insecure or unwilling), and R4 (Able, confident and willing. The SLM matches leadership styles to readiness levels of employees as shown in the designations and in figure 1 below:

S1 designates leaders who define the roles and task of followers and supervise, direct and guide followers very closely. These leaders make all the decisions, and authority is from top to bottom. In other words, such leaders are referred to as "telling leaders." The model recommends the application of this type of leadership style be applied to subordinates with low competence but with high commitment level (Readiness level 1: R1).

$S 2$ designates leaders who still define, explain, and persuade followers to do their roles and task, but remains open to ideas and suggestions from followers. Such leaders encourage two-way communications, but the decision remains the prerogative of the leader. Some experts refer to such leaders as "selling leaders." The model proposes the use of the selling type of leadership style for subordinates with some competence but low commitment (Readiness level 2: R2).

S3 designates participating or supporting leaders who relay day-to-day decisions to followers. Such a leader encourages, facilitates, and takes part in the problemsolving process and decisions, but control lies in the hands of the followers. The S3 type of leadership style is appropriate for subordinate with high competence, but with variant commitment levels (Readiness level 3: R3). In this type of leadership, the subordinate participates in the decision-making process guided by the leader.

$S 4$ refers to delegating leaders who are still involved in the decision-making and problem-solving process but relinquishes control of individual tasks with the followers. The leader is mainly concerned with monitoring, observing, and evaluating. The SL model recommends the S4 type of leadership style for subordinates with high competence and high commitment level (Readiness level 4: R4).

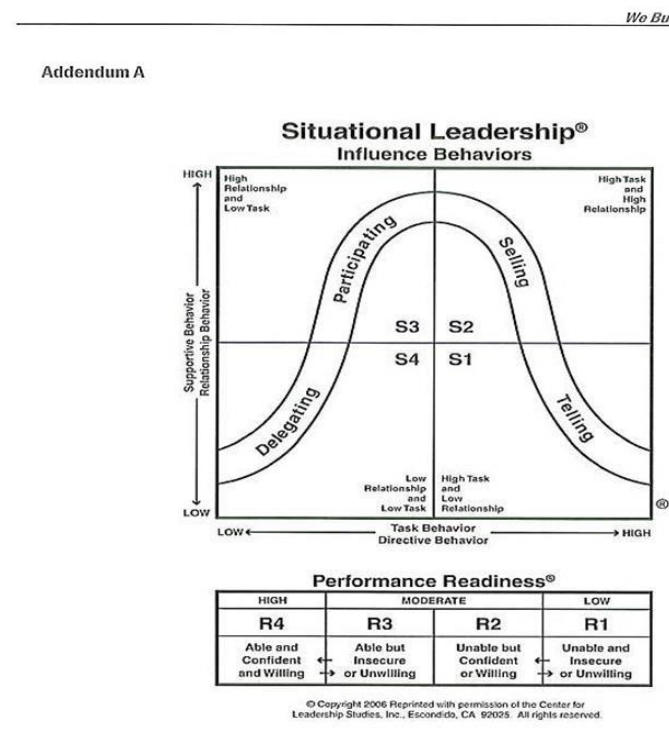

Figure 1. The Situational Leadership ${ }^{\circledR}$ Model. Adapted from Blanchard, K. H., Hersey, P., Johnson, D., E. (2013). Management of organizational behavior: Leading Human Resources. (10th ed.). Englewood Cliffs, NJ: Prentice-Hall.

The SLM model has been tested using various instruments including the Leadership Effectiveness Adaptability Descriptor (LEAD) instrument; the Manager Rating Scale (MRS), and the Staff Member Rating Scale (SMRS) (Hersey, et al., 2013). The Manager Rating Scale measures the managers' perception of the follower's psychological and ability readiness to complete a specific task, while the Staff Member Rating Scale measures the employee self-rated readiness. The LEAD Instrument provides insight into the leadership style, style range, and style adaptability. Leadership style was designated as the leadership behavior exhibited by the leaders as perceived by the leaders themselves and others. Style range was designated as the extent to which the leaders were able to vary the leadership style, and style adaptability was designated as the extent to which leaders were able to vary the leadership style to match the readiness level of the follower in a specific situation. These three instruments and a demographic survey were used in this study to answer the research questions and to provide more insight into the study.

\section{B. Literature Review}

Employee readiness is one of the most important factors in human capital development and management. Unfortunately, many employers overlook the concept, instead emphasizing other determinants of employee turnover such as low salaries, lack of benefits, lack of promotion, relocation, and so on. The situational variable in the SLM model is employee readiness relative to performing a specific or given task. Readiness, according to Hersey et al. (2013), is the extent to which a follower has the ability and willingness to accomplish a specific task. Employee readiness has two dimensions, namely, 
psychological readiness and ability/job readiness. Willingness, on the other hand, refers to the employee's willingness to take responsibility for directing his or her own behavior in completing a given task. Employee willingness includes the extent to which the employee was confident, motivated, and committed to accomplishing a task (Hersey et al, 2013). Hersey et al also noted that low achievement in an employee affects the willingness or readiness of that employee. An employee with low motivation may likely result in low achievement, who may consequently become a prime candidate for quitting his or her job. While examining employee ability or job readiness, Hersey el al. (2013) suggested that the competence level of the employee was very important, and that the ability for an employee to complete a given task was achieved by acquiring knowledge and skills. The knowledge and skills developed for a particular job may be very helpful for retention among employees. Herman (2019) noted the importance of job readiness programs. Herman noted that job readiness programs may help to teach individuals how to keep a job once they get one and also help individuals develop good work ethics. Herman suggested that instruction in showing up to work on time, being a good team member, having a good attitude, and being helpful on the job may be part of a job retention curriculum. As a recommendation, Herman advanced that the acquisition of knowledge and skills was determined by education and/or work experience, and as such, it is the duty of employers to provide training concurrently with the availability of resources for employees to do their job. Effective training and availability of resources may help reduce job stress among employees. Job stress and job overload are ingredients for many employees deciding to quit their jobs. To help reduce employee turnover and/or intentions to quit their jobs, Herman reported that job training helps employees to gain the ability and confidence in themselves to complete a given task. The more success an employee has in completing a task, the more motivated and "readier" that employee becomes, hence, more likely to stay on the job.

An employee who lacks confident and is unmotivated may likely become uncommitted and eventually may turnover or decide to leave the job. Job commitment and readiness may have a strong positive correlation, as does reduced turnover which has a very strong correlation with organization commitment. Mowday et al. (1982) reported that there exists an indirect relationship between commitment and turnover because of the involvement of other factors or variables such as the desire to stay, and the intention to search for a different job. This intent to quit or turnover was measured by Jackofsky and Slocum (1987) by developing a turnover scale, which measures the individual's thought of quitting and intent to leave. In another study, Chen and Silverthorne (2005) reported a positive correlation between ability and willingness, employee job satisfaction, and job performance. The researchers found employee willingness to be positively correlated with job satisfaction and job performance but was negatively correlated with turnover intention.
Ćulibrk, Delić, Mitrović, and Ćulibrk (2018) determined that job involvement or employee readiness has a mediating role between job satisfaction and organizational commitment, resulting in employee job satisfaction and commitment. Deploying some of the strategies advanced by researchers may help resolve some of these turnover issues plaguing organizations, especially healthcare organizations. Rosenbaum (2018) wondered whether managers and administrators would finally resolve turnover issues in their organizations in 2018, as turnover continued to be a serious problem for many businesses including healthcare businesses. Long term care facilities are very notorious for employee turnover and in some cases consider turnover to be a norm (PointClickCare, 2016). In some cases, employees are not psychologically prepared to work in stressful environments. As a result, some of these employees may find themselves burnt-out and may seek for other less stressful opportunities. Psychological readiness is one of the most essential conditions for successful selfrealization in professional life. It involves a conscious choice of a profession in accordance with the person's (a) skills and abilities, (b) awareness of his/her own needs, (c) demands of the society, (d) team, (e) set goals, (f) manifestation of their intellectual, emotional and willed processes, (g) the correlation between personal capabilities, (h) level of aspiration and (i) necessary achievements in something. A person's psychological readiness to complete a given task determines his/her competitiveness and potential for success or retention on a job. The Association for Psychological Science (2014) suggested that managers must emphasize on identifying employees at the highest risk of quitting before they exit the job. This proactive approach may help prevent turnover because these managers may work with such employees by making certain reasonable adjustments to lighten their burden and getting them the necessary resources to enhance their job competencies. This idea of identifying stressed employees was also buttressed by Fraccaroli, (2014) in his study on social identity and social exchange approach. The researcher reported that based on the social identity model, the perceived organizational support resulting from identification should lead to less emotional exhaustion and lower turnover intentions among employees.

The argument here is, if leaders comply with the dictates of the SLM model, there is tendency a that employee turnover, tardiness, and dissatisfaction will be reduced. Therefore, if the SLM model holds, then a ready/mature/willing/developed employee will be less likely to turnover, all other things remaining constant.

\section{METHODOLOGY}

\section{A. Procedure}

The sampling process targeted supervisors $(\mathrm{N}=60)$ and subordinates $(\mathrm{N}=320)$ randomly selected from four randomly selected hospitals within the southern region of the United States. The sample size was selected was done by $\mathrm{G}^{*}$ Power analysis. Out of the supervisors $(\mathrm{N}=60)$ and 
subordinates $(\mathrm{N}=320)$, a total of supervisors $(\mathrm{N}=48)$ and subordinates $(\mathrm{N}=192)$ were accepted for analysis with a questionnaire return rate of $63.2 \%$. Participation was voluntary, and all responses were treated with anonymity. Three types of instruments were used in the study: (a) The Manager Rating Scale, which measured supervisor's perception of their leadership style and the readiness level of the subordinate; (b) The Staff Member Rating Scale, which measures their perception of the match between their readiness level and their supervisor's leadership style, (c) The Jackofsky and Slocum (1987) Turnover Intent Scale, which measures employee turnover intent, and (d) demographic questionnaires designed by the researcher used to collect demographic information such as age, educational level, years of experience, and gender. Participants demographics were used for descriptive purposes, and to provide a better insight into the research question.

Informed consent forms were filled by participants and their identities were concealed using codes. Participants could quit the study at any time without any penalty. There was no compensation of participants and their participation was voluntary.

\section{A. Instruments}

\section{i) Readiness Scale}

The Situational Leadership Model posits that leadership effectiveness was generated when the leader assessed correctly the follower's readiness level and applied the appropriate style for that level. To help both leaders and followers make valid and reliable judgments about follower perceived readiness, two instruments were developed to measure employee total readiness: Manager Rating scale and Staff Member Rating scale (Hambleton et al., 1977). Each of the instruments consisted of two 10item subscales that measure psychological and job readiness on an eight-point scale. The purpose of the Readiness Scale was to help a manager and their staff members ascertain their perceived readiness levels in relation to five specific tasks. The Readiness Scale called for leaders to determine the readiness of a staff member on each of five tasks in isolation. The questionnaire contains a Critical Task Inventory to provide clarity about which tasks should be focused on, thus generating alignment of the follower's effort with leaders, teams and/or organizational goals. Similarly, the Staff Member Readiness scale asks the followers to determine their own readiness on each of five tasks. The scale also includes a Critical Task Inventory, which may be chosen to align with the Manager's to assist in outlining their readiness on specific tasks.

In both assessments, total ability and total willingness scores were obtained, allowing each party to examine where their perceptions differ, and to gain useful insight into where performance gaps might lie. A pathway for building more effective working relationships was established. This occurred because the leaders were able to meet the follower's needs on a task-by-task basis, thus encouraging appropriate levels of performance based on actual leadership styles matching actual readiness levels (Center of Leadership Studies, 2016). Scores for ability readiness and psychological readiness are computed to get total readiness scores. The readiness scores fall within the range of low, moderate, and high readiness.

\section{ii) Turnover Scale}

Jackofsky and Slocum's (1987) Turnover Intention scale was used to measure turnover variables, such as the thought of quitting and the intent to leave. The items on the scale, that is, "thought of quitting" and "intent to leave" were antecedents of turnover. Each scale comprised of four items, which were rated on a five-point Likert scale ranging from strongly agree to strongly disagree. The Thoughts-Of-Quitting scale was found to have reliability of $r=0.83$. In addition, the Intention - To Quit Scale had a reliability of $r=0.73$ (Jackofsky \& Slocum, 1987).

\section{iii) Demographic Survey}

The demographic survey was used to collect demographic data (Age, Gender, Educational level, Experience on the job, etc.) to help provide more insight into the study sample.

The survey was administered in a paper and pencil format to willing participants after consultations with the Human Resources department and managers supervising participants in the four hospitals. Multiple visits were made to these facilities to secure approval for the study and informed consent from participants. The researcher made sure all ethical considerations were covered and addressed all concerns of the participants. Surveys, with a self-addressed return, envelopes were distributed to participants via the human resources department. Participants were asked to return completed surveys directly via post or via the human resources offices of their respective hospitals. Participants were given two weeks to complete surveys.

\section{B. Data Analysis}

Two types of analysis were done: Descriptive analysis and hypothesis testing.

i) Descriptive Statistics: The descriptive analysis was performed to provide more insight into the study, and it yielded the following results: TABLE 1 shows the distribution of demographic characteristics of participants starting with age distribution. The age group $(20-30)$ had 61 participants 61/240 (25.4\%), (31 - 41) had more participants $96 / 240(40 \%)$, (42 - 52) years $64 / 240(26.7 \%),(53-63)$ had $15 / 240$ participants $(15 \%)$, and $(64-74)$ having the least number of participants $4 / 240(1.7 \%)$ compared to all other age groups.

The next demographic variable was gender. There were more female respondents 142/240 (59.2\%) than males $98 / 240$ (40.8\%). Regarding the educational level, $100 / 240(41.7 \%)$ of the participants had high school diplomas and 90/240 (37.5\%) had earned an Associate Degree. Out of the $20.7 \%$ remaining, $17.1 \%$ had a 
bachelor's degree, $3.3 \%$ had a master's degree, and $0.4 \%$ had a doctorate degree. Regarding experience on the job, $77.9 \%$ had at least 10 years of experience on the job,
$19.2 \%$ had at least 11 years on the job, and $2.5 \%$ had at least 25 years on the job. These results are available on TABLE 1 below:

\section{TABLE I. NUMBER AND PERCENTAGES OF PARTICIPANTS}

\begin{tabular}{|c|c|c|}
\hline Demographics characteristics & $\mathrm{n}$ & $\%$ \\
\hline \multicolumn{3}{|l|}{$\overline{A g e}$} \\
\hline $20-30$ & 61 & 25.4 \\
\hline $31-41$ & 96 & 40.0 \\
\hline $42-52$ & 64 & 26.7 \\
\hline $53-63$ & 15 & 6.2 \\
\hline $64-74$ & 4 & 1.7 \\
\hline \multicolumn{3}{|l|}{ Gender } \\
\hline Male & 98 & 40.8 \\
\hline Female & 142 & 59.2 \\
\hline \multicolumn{3}{|l|}{ Educational level } \\
\hline High school & 100 & 41.7 \\
\hline Associates & 90 & 37.5 \\
\hline Bachelors & 41 & 17.1 \\
\hline Masters & 8 & 3.3 \\
\hline Doctorate & 1 & 0.4 \\
\hline \multicolumn{3}{|l|}{ Experience in years } \\
\hline $1-5$ & 105 & 42.5 \\
\hline $6-10$ & 85 & 35.4 \\
\hline $11-15$ & 35 & 14.5 \\
\hline $16-20$ & 11 & 4.6 \\
\hline $21-25$ & 7 & 2.9 \\
\hline
\end{tabular}

\section{RESULTS}

The researcher conducted further analyses into the turnover intent scale. Table 2 represents distribution on the question: "I will quit my job soon."
More than 50 percent of the participants disagree about quitting their jobs soon. That was the same trend for those responding to the question of "I often think of quitting my present job.” (see table 3). 


\section{TABLE II. DISTRIBUTION OF STATEMENT "I WILL QUIT MY JOB SOON" Job Category}

\begin{tabular}{lccc} 
Statement & Clinical staff & Nonclinical staff & Total \\
\hline Strongly disagree & 53 & 46 & 99 \\
Disagree & 53 & 58 & 111 \\
Neither agree nor disagree & 0 & 8 & 8 \\
Agree & 6 & 4 & 10 \\
Strongly agree & 8 & 4 & 12 \\
Total & 120 & 120 & 240 \\
\hline
\end{tabular}

\section{TABLE III. DISTRIBUTION OF STATEMENT "I OFTEN THINK OF QUITTING MY PRESENT JOB"} Job Category

\begin{tabular}{lccc} 
Statement & Clinical staff & Nonclinical staff & Total \\
\hline Strongly disagree & 42 & 43 & 85 \\
Disagree & 50 & 57 & 107 \\
Neither agree nor disagree & 16 & 12 & 28 \\
Agree & 4 & 5 & 9 \\
Strongly agree & 8 & 3 & 11 \\
Total & 120 & 120 & 240 \\
\hline
\end{tabular}

The next rounds of tests conducted were hypotheses testing:

\section{ii) Hypotheses Testing}

Before any hypotheses testing was done, the researcher performed exploratory data analysis which consisted of three tests: test for reliability, test for outliers, and test for normality. The researcher performed a reliability analysis test of the Jacoskofsky and Slocum Turnover intent scale and obtained calculated Cronbach's alpha $(\alpha)$ of 0.7 . This value was the same with the acceptable level of $\alpha \geq .70$ (Gliem \& Gliem, 2003). The Test of Outliers was evaluated for the same Turnover Intent Scale using boxplots to get rid of any undue influence on the results in hypothesis testing, but the records were retained because of lack of significant differences in the data. The researcher evaluated the distribution of variables for normality using the Kolmogoroff-Smirnov (K - S) test. The results showed that the $p$-value is less than .05 , which meant that the variables were normally distributed. For the Readiness Scale, the researcher relied on the original validity of the scale. The Readiness Scale has a test-retest reliability of .84 on the Ability Scale and .88 on the Readiness Scale (Hambleton et al., 1977). The researcher relied on the original validity of the Readiness Scale and its reliable use over time.
To answer research question 1: What is the relationship between staff member perceived self-rated and supervisor perceived rated job, psychological, and total readiness? A Pearson Correlation Matrix test was conducted for SRJR, SRPR, SSRJR, SSPR, SSRTR, and TI. Results are presented in TABLE V below. There was sufficient evidence to show that a significant positive correlation existed between staff member self-rated job readiness (SRJR) and staff self-rated psychological readiness (SRPR) $r=.837, p=.000$, supervisor rated staff job readiness (SSRJR) and psychological readiness (SSRPR) $r=.843, p=.000$, staff self-rated job readiness (SRJR) and supervisor rated staff psychological readiness (SSRSPR) $r=.832, p=.000$.

To answer research question 2: What is the relationship between staff member and supervisor perceived job, psychological, total readiness, and TI? A Pearson Correlation matrix test was conducted for SRJR, SRPR, SRTR and TI; and SSRJR, SSPR, SSTR and TI. The results are presented on TABLE IV below. There was significant negative correlation between job readiness, psychological readiness, total readiness and turnover intentions: [TI - SRJR $(r=-.143, p=.026)$, TI - SRPR $(r=-.133, p=.040)$, TI $-\operatorname{SSRSJR}(r=-.140, p=.030)$, TI - SSRPR $(r=-.137, p=.034)]$. The results are displayed below. 
TABLE IV. PEARSON CORRELATION MATRIX OF SRJR, SRPR, SSRSJR, SSPSR, SSRTR, and TI

\begin{tabular}{|c|c|c|c|c|c|c|c|}
\hline Variable & 1 & 2 & 3 & 4 & 5 & 6 & 7 \\
\hline 1. TI & - & $-.143 *$ & $-.133 *$ & $-.144^{*}$ & $-.140 *$ & $-.137 *$ & $-.145^{*}$ \\
\hline 2. SRJR & $-.143 *$ & - & $.837 * *$ & $.956 * *$ & $.994 * *$ & $.832 * *$ & $.948 * *$ \\
\hline 3. SRPR & $-.133^{*}$ & $.837 * *$ & - & $.961 * *$ & $.848 * *$ & $.993 * *$ & $.961 * *$ \\
\hline 4. SRTR & $-.144 *$ & $.956^{* *}$ & $.961 * *$ & - & $.959 * *$ & $.954 * *$ & $.996 * *$ \\
\hline 5. SSRJR & $-.140 *$ & $.994 * *$ & $.848 * *$ & $.959 * *$ & - & $.842 * *$ & $.957 * *$ \\
\hline 6. SSRPR & $-.137 *$ & $.832 * *$ & $.993 * *$ & $.954 * *$ & $.842 * *$ & - & $.962 * *$ \\
\hline 7. SSRTR & $-.145^{*}$ & $.948 * *$ & $.961 * *$ & $.996 * *$ & $.957 * *$ & $.962 * *$ & - \\
\hline
\end{tabular}

Note. SRJR = Staff Rated Job Readiness, SRPR = Staff Rated Psychological Readiness, SSRSJR = Supervisor Rated Staff Job Readiness, SSPSR = Supervisor Rated Staff Psychological Readiness, SRTR = Staff Rated Total Readiness, SSRSTR = Supervisor rated Staff Total Readiness, and TI = Turnover Intent.

*Correlation significant at .05 level (2-tailed). **Correlation significant at .01 level (2-tailed).

To answer research question 3: Are there differences in mean scores between clinical and non-clinical employees in relation to their total readiness perceptions? An independent $t$ - test was conducted test for significant differences in mean total readiness scores for clinical and non-clinical staff. The results and statistics are presented in TABLE V below. The results of the $t$ test revealed a statistically significant difference between the mean scores of total job readiness for clinical $(M=34.05, s=3.73$ and nonclinical staff $(M=32.69, s=$ 3.18), $t(190)=2.71, p=.007, \alpha=.05$.

TABLE V.

INDEPENDENT $T$ - TEST FOR CLINICAL AND NONCLINICAL STAFF SELF RATED TOTAL READINESS Levene's test for equality of means $\quad T$-test for equality of means

$95 \%$ confidence

\begin{tabular}{llllllllllll}
\hline & & \multicolumn{1}{c}{} & \multicolumn{3}{c}{ Mean } & \multicolumn{2}{c}{$S D$ error } \\
& $F(2$-tailed) & Sig. & $t$ & $d f$ & Sig. & difference & difference & Lower & Upper \\
\hline Equal variances & 2.31 & .13 & 2.71 & 190 & .007 & 1.35 & .50 & .36 & 2.34 &
\end{tabular}

assumed

Equal variances not

$\begin{array}{lll}2.71 & 185.4 \quad .007\end{array}$

1.35

.50

.36

2.34

assumed

\footnotetext{
Note. SRJR = Staff Rated Job Readiness, SSRJR = Supervisor Rated Staff Job Readiness, SRPR = Staff Rated Psychological Readiness, SSRPR = Supervisor Rated Staff Psychological Readiness, SRTR = Staff Rated Total Readiness, SSRTR = Supervisor Rated Staff Total Readiness.
}

To answer research question 4: Are there differences in mean scores between staff member self-rated and supervisor rated job, psychological, and total readiness? A paired $t$ - test was conducted to examine any differences in mean scores between staff member selfrated and supervisor rated job, psychological, and total readiness (SRJR - SSRJR; SRPR - SSRPR; and SRTR SSRTR). Results are presented in TABLE VI below. The mean scores and standard deviations were, Pair 1 (SRJRSSRJR) were $(M=15.76-15.77)$ and $(S D=3.16-3.02)$, respectively; Pair 2 (SRPR-SSRPR) were $(M=17.58-$ 
17.47) and $(S D=2.52-2.49)$, respectively, Pair 3 (SRTRSSRTR) were $(M=33.38-33.26)$ and $(S D=3.52-3.32)$, respectively. The paired $t$ test results failed to show enough evidence of significant differences between Staff
Rated Readiness Scores and Supervisor Rated Readiness Scores, pair 1 (SRJR-SSRJR) $t(191)=-.089, p=.931$; pair 2 (SRPR-

SSRPR) $t(191)=1.55, p=.123$; pair 3 (SRTR-SSRTR) $t(191)=1.26, p=.21$. All tests were done at $\alpha=.05$

TABLE VI. STATISTICS AND RESULTS OF THE PAIRED T - TEST FOR SRJR-SSRJR; SRPR-SSPR; and SRTR-SSTR

\begin{tabular}{lllllllll}
\hline \multicolumn{1}{c}{$M$} & $N$ & $S D$ & $d f$ & $S E M$ & $F$ & Sig. \\
\hline Pair 1 & & & & & & & & \\
& SRJR & 15.76 & 192 & 3.16 & 191 & .23 & -.09 & .93 \\
& SSRSJR & 15.77 & 192 & 3.02 & & .22 & & \\
Pair 2 & & & & & & & & \\
& SRPR & 17.58 & 192 & 2.52 & 191 & .18 & 1.55 & .12 \\
& SSRSPR & 17.47 & 192 & 2.49 & & .18 & & \\
Pair 3 & & & & & & & & \\
& SRTR & 33.38 & 192 & 3.52 & 191 & .25 & 1.26 & .21 \\
& SSRSTR & 33.26 & 191 & 3.32 & & .24 & &
\end{tabular}


Job Readiness, SSPSR = Supervisor Rated Staff Psychological Readiness, SRTR = Staff Rated Total Readiness, SSRSTR = Supervisor Rated Staff Total Readiness

\section{DISCUSSION}

The purpose of the study was to examine the relationship between employee readiness and turnover intent among hospital employees. The study made use of SLT as the conceptual framework in collaboration with the Staff Member Self-Rated Readiness Scale and Manager Rating Scale. The SLM was tested among 240 total participants, of which 48 were supervisors and 192 were their subordinates from four randomly selected hospitals. Supervisors were asked to complete demographic surveys, as well as Manager Rating scale, which rates supervisor's perception of their staff or subordinate job and psychological readiness; and the Jackofsky and Slocum Turnover Intent scale, which measures employee turnover intent. Staff, on the other hand, were asked to complete demographic surveys, Staff Member Rating scale, which rates staff member job and psychological readiness; the Jackofsky and Slocum's Turnover Intent scale, which measure employee turnover intent, and Demographic surveys. The responses were scored as directed by the Center of Leadership Studies (2016) and the results were analyzed using the statistical software SPSS 24.0.

The basic premise of SLM is that effective leaders match their leadership styles to the readiness level of the follower. Therefore, if this match is effectively executed, the result would be reduced absenteeism, enhanced employee retention and reduction of turnover, and enhanced employee productivity. The case here is; employee readiness should be related to turnover intent among subordinates. If employees are task ready, as well as psychologically ready for a job, then job readiness should be inversely related to turnover intentions among employees, all other things remaining constant. This premise formed the basis for this investigation.

\section{A. Employee Readiness}

Employee readiness is the situational variable in Situational Leadership relating to the employees' ability and willingness to accomplish a specific task. Hersey and Blanchard argued that for a leader to be effective, that leader must match his or her leadership style with the readiness/developmental/maturity level of the follower. That is, S1 matches with R1, S2 with R2, S3 with R3, and S4 with R4. In this study, staff self-rated job readiness had a mean score of 15.76 with standard deviation of 3.15; while supervisor rated staff job readiness mean score was 15.76 with standard deviation of 3.01. Staff self-rated psychological readiness mean score was 17.58 with standard deviation of 2.51, while supervisor rated staff psychological readiness was 17.47 with standard deviation 2.48. To test for significant differences in mean scores between staff rated and supervisor rated readiness scores, a paired $t$ test was conducted for the four variables. Results of the paired $t$ test indicated there was insufficient evidence to show that staff rated job readiness, psychological readiness, 
and total readiness scores were significantly different from supervisor rated readiness scores. Results showed that staff self-rated and supervisor rated job readiness scores $t(191)=.089, p=.931$; staff self-rated and supervisor rated psychological readiness scores $t(191)=$ $1.55, p=.123, \alpha=.05$; staff self-rated and supervisor rated total readiness $t(191)=1.26, p=.21, \alpha=.05$. Correlation results were as follows: $r=.994, r=.993$ and $r=.996$ for job, psychological and total readiness, respectively. Overall, supervisors and staff had similar perceptions in terms of staff readiness to carry out their respective tasks. However, when participants were categorized into clinical and nonclinical staff, the $t$-test revealed a statistically reliable difference between the mean scores in terms of staff self-rated total job readiness for clinical $(M=34.05, s=3.73)$ and nonclinical staff $(M=32.69, s=3.18), t(190)=2.71, p$ $=.007, \alpha=.05$. This finding was consisted with the findings of Knight and Hal (1991). From the results, it was clear that clinical and nonclinical staff do not have similar readiness in performing their tasks. Overall, employee readiness was negatively correlated to employee turnover intentions. This finding was similar to the finding of Chen and Silverthorne (2005). It was not a surprise to observe that both staff and supervisors gave higher ratings on the Staff Readiness scale. Out of a possible range of $0-40$, the lowest score of 22 and the highest was 40 . The mean score for total readiness as rated by supervisors was 33.26 and staff was 33.38 . The reason for this may be (a) employees do not normally give themselves negative ratings in an external environment, (b) the employees may have had close professional relationships to the extent that staff are very confident of themselves, and (c) supervisors know the capabilities of their staff.

\section{B. Principal Findings of the Study}

The results of the investigation advanced the following logical inferences from the data analysis.

- More than 50 percent of the employees tend to disagree with any statement alluding to turnover from the survey. The trend was similar among clinical and nonclinical employees. In this study, the overall turnover intention scores among employees were low.

- $\quad$ An independent sample $t$-test revealed statistically reliable evidence of significant difference between clinical and nonclinical employees in their relation to turnover. This shows differences in task and readiness among employees based on their job responsibilities.

- $\quad$ The paired $t$-test did not reveal any significant difference in mean scores between staff rated job, psychological, and total readiness scores and the manager rated scores. This shows that the subordinates and managers are in synch relative to subordinates' job and psychological readiness. It is evident that managers and subordinates are in close working relationship. For a healthcare facility to function efficiently, one of the vital ingredients should be a good leader-follower relationship. This attribute is critical for employee readiness and turnover intent.

- The Pearson Correlation Matrix revealed that employee readiness (Job, psychological, and total readiness) was negatively correlated to turnover intentions. Consistent with the results of the paired $t$-test and the fact that more than 50 percent of the participants disagree with turnover intentions, employee readiness was negatively correlated with turnover intentions. Employees showed high job, psychological, and total readiness consistent with flexibility shown by their managers. Hence employees would not want to turnover because they work well with their managers, all other things remaining constant.

\section{B. Recommendations and Implications for Further Study}

Retention of employees has been a problem for many organizations for several years and has cost organizations millions of dollars every year. To help alleviate this problem, the following recommendations are advanced based on logical inferences drawn from the study.

1. Healthcare organizations must address employee turnover effectively by working on strategies that could improve employee readiness. One of those strategies could be focusing on supervisor leadership style because, leadership style has a lot to do with staff readiness and hence, the decision to turnover or stay. Managers play a very important role in employee total readiness, both in the completion the of tasks and in the acquisition of competencies through the use of training programs, that gives the employee the mental confidence psychological readiness on the job. An employee's decision to stay or leave a job depends on the necessary resources available for the employee to complete the task, training receives, and mind frame. Supervisors have significant impact on employee retention and turnover. A frequent conflict between employees and their managers is not healthy for employee retention.

2. Hospitals should put measures in place that holds managers responsible for turnover rates. Periodic reviews of employee satisfaction of supervisor's performances should be done. The review should examine the manager's leadership style, and resources for employees to carry out their tasks, including training, job security, benefits and so on.

3. Managers must set a tracking system in place to identify employees who make likely turnover. The tracking system may include items like poor performance, tardiness, low ability, and so on. These may be indicators for future trends, but not a guarantee of turnover.

4. The study has taken the initiative to explore differences between clinical and nonclinical 
employees, a subgroup in the healthcare industry, and has laid a groundwork for further studies. More studies are needed with a larger sample size, and more subgroups, in a different environment to confirm results of this investigation.

5. Finally, review of related literature supports the SLM, that is, leadership style is most effective when leaders vary their leadership styles based on the readiness level of the follower. This investigation supported the notion that when a leader matches his/her leadership style according to the readiness of the follower, turnover is reduced. It is the position of the researcher that this study could make valuable contributions to leader-follower relationship, and hence help reduce, absenteeism, employee turnover, improve quality of care, and guide hospital administrators, managers, supervisors, and stakeholders in their pursuit of excellence to achieve organizational goals.

\section{CONCLUSION}

The relationship between employee readiness and turnover intentions was investigated among hospital employees using the Situational Leadership Model as the conceptual framework. Supervisors and their subordinates were invested using the Staff and Manager Readiness Scale. Staff rated their job and psychological readiness, and managers were asked to rate their subordinates' readiness to complete a task. There was no difference between the two ratings. The premise of the investigation was that, if managers vary their leadership styles based on the readiness level of their employees, there is a tendency that employee readiness is enhanced, and turnover is reduced. The results of the study revealed a negative correlation between employee readiness and turn over intentions. There was significant difference between clinical and non-clinical staff when readiness was compared with turnover intent scores.

\section{REFERENCES}

Alkhawaja, A. (2017). Leadership style and employee turnover: A mythical relationship or reality.

Retrieved from

http://digital.sandiego.edu/cgi/viewcontent.cgi? article $=1016 \&$ context $=$ solesmalscap

Association for Psychological Science (2014).

Preventing job turnover by identifying what makes people seekers or stayers. Retrieved from https://www.psychologicalscience.org/news/mi nds-business/preventing-job-turnoverbyidentifying-what-makes-people-seekers-orstayers.html

Blanchard, K. H., Hersey, P., Johnson, D., E. (2013).

Management of organizational behavior: Leading Human Resources. (10th ed.). Englewood Cliffs, NJ: Prentice-Hall.

Center of Leadership Studies. (2016). Leadership effectiveness and adaptability description scoring matrix. Escondido, CA: Leadership Studies.

Chen, J., \& Silverthorne, C. (2005). Leadership effectiveness, leadership adaptability, and employee readiness. Leadership and Organizational Development Journal, 26(3/4), 280-289.

Ćulibrk, J., Delić, M., Mitrović, S., \& Ćulibrk, D.

(2018). Job satisfaction, organizational commitment and job involvement: The mediating role of job involvement. Frontiers in Psychology, 9, 132. doi:10.3389/fpsyg.2018.00132

Fraccaroli, F. (2014). Staying or leaving: A combined social identity and social exchange approach to predicting employee turnover intentions. International Journal of Productivity and Performance Management. DOI: 10.1108/IJPPM-02-2013-0028.

Gliem, J. A, \& Gliem, R. R. (2003). Calculating, interpreting, and reporting Cronbach's alpha reliability coefficient for Likert-type scales. Retrieved from http://pioneer.netserv.chula.ac.th/ ppongsa/201 3605/Cronbach.pdf

Hambleton, R. K., Blanchard, K. H., \& Hersey, P.

(1977). Maturity Scale-Self-rating forms. San Diego, CA: Learning Resource Corporation.

Herman, A. (2019). Workforce development and online learning. Retrieved from https://www.affordablecollegesonline.org/work force-development-guide/

Jackofsky, E, J., \& Slocum, J. W. (1987). A Causal

analysis of the impact of job performance on voluntary turnover. Journal of Occupational Behavior, 8, 263-270.

Mowday, R. T., Porter, L. W., \& Steers, R. M. (1982).

Employee-organizational linkages: The psychology of commitment, absenteeism, and turnover. New York, NY: Academic Press.

Norman, L. (2017). What is job readiness training?

Retrieved from https://bizfluent.com/info7916466-jobreadiness-training.html 
PointClickCare (2016, Dec. 22). Why turnover has become unacceptable in long term-care. Retrieved from https://blog.pointclickcare.com/turnoverunacce ptablelong-termcare/

Rosenbaum, M. (2018). Will 2018 be the year

healthcare addresses its turnover problem? Retrieved from https://www.beckershospitalreview.com/financ e/will-2018-be-the-year-healthcare-addressesits-turnoverproblem.html

Silverthorne, C. (2005). Leadership effectiveness, leadership style and employee readiness, Leadership \& Organization Development Journal, 26, (4), 280 - 288. Doi:https://doi.org/10.1108/01437730510600652

Sanjee, S. J. (2017). Employee Readiness for Organizational Change: A Case Study in an Export Oriented Manufacturing Firm in Sri Lanka. Eurasian Journal of Business and Economics, 10(20),1 - 16. Doi: 10.17015/ejbe.2017.020.01 